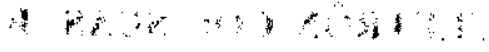

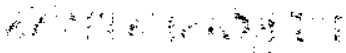

\title{
O PROCESSO CIVIL ELETRÔNICO: SUAS BASES PRINCIPIOLÓGICAS E LEGISLATIVAS
}




\title{
O PROCESSO CIVIL ELETRÔNICO: SUAS BASES PRINCIPIOLÓGICAS E LEGISLATIVAS
}

\author{
Débora Regina Honório Galan
}

\section{RESUMO:}

O presente trabalho se pauta pela aplicação do meio eletrônico ao processo civil brasileiro com vistas à instrumentalidade do processo, demonstrando sua evolução legislativa e a possibilidade de sua utilização estribada em princípios constitucionais.

O sistema processual moderno é concebido a partir da Constituição Federal, a qual abriga os princípios e valores que devem nortear a atividade processual. Dos princípios constitucionais considerados basilares, princípio do acesso à justiça e do devido processo legal, decorrem outros, dos quais destacam-se ao tema em tratamento os seguintes: princípio da efetividade e da celeridade processual, bem como os princípios da instrumentalidade das formas e da economia processual.

Para a concretização desses princípios, necessária se mostra a revisão de conceitos e velhos dogmas da ciência processual para o fim de alcançar os valores albergados na Carta Magna, em atenção ao entendimento de que a efetividade do processo está estreitamente relacionada com o seu tempo de duração, assim como a presteza da atividade jurisdicional está intimamente ligada ao acesso à justiça.

Nesse contexto, as inovações tecnológicas precisam ser absorvidas no âmbito processual. O processo eletrônico, assim denominado porque seu procedimento utiliza meios físicos que são o objeto de estudo da parte da física chamada eletrônica, representa um contundente passo dado na direção da concretização daqueles princípios processuais.

Analista Judiciária do Tribunal de Justiça do Estado do Tocantins.Atualmente lotada na Assessoria Acadêmica e Pedagógica da Escola Superior da Magistratura Tocantinense. Pósgraduada (lato sensu) em Novo Direito Civil, pela Fundação Universidade do Sul de Santa Catarina - UNISUL e IELF. Artigo Jurídico apresentado como trabalho de conclusão do curso de pós-graduação lato sensu televirtual em Direito Processual Civil da Universidade Anhanguera UNIDERP e Instituto Brasileiro de Direito Processual - IBDP, pela Rede de Ensino Luiz Flávio Gomes - Rede LFG. E-mail: drhgalan@gmail.com 
Palavras-chave: Princípios constitucionais. Acesso à justiça. Efetividade do processo. Celeridade. Evolução legislativa. Processo eletrônico.

\section{ABSTRACT:}

The present study is about the application of electronic means to Brazilian civil process considering the procedure as an instrument, demonstrating its legislative evolution and the possibility of its utilization based on constitutional principles.

The modern system of proceeding is conceived from the Federal Constitution, which brings the principles and values that must guide the process activity. From the constitutional principles considered in the base, the principle of access to justice and the due process of law, there are others, which can be related to the studying theme the following: the principle of effectiveness and the procedure celerity, as well as the principles of instrumentality of forms and procedural economy.

To make these principles real, it is necessary to review the concepts and old beliefs of law science in order to achieve the values protected by the Constitution, in attention to the understanding that the effectiveness of process is nearly related to its time of duration, the same as the results of jurisdictional activity is nearly related to access to justice.

In this context, the new technologies need to be absorbed in matters of process. The electronic procedure, so called due to the use of physical means that are the object of study of part of the Physics called electronics, represent an important step in direction of realizing those procedural principles.

Keywords: Constitutional principles. Access to justice. Effectiveness of the process. Celerity. Legislative evaluation. The eprocess. 


\section{INTRODUÇÃO}

$\mathrm{O}$ presente artigo tem por objetivo realizar uma exposição do denominado processo eletrônico, introduzido explícita e genericamente no sistema processual brasileiro pela Lei ${ }^{\circ} 11.419 / 06$, realizando um embasamento principiológico nos valores estampados na Constituição Federal e trazendo um rastro legislativo que demonstra as origens e evolução da instrumentalidade do processo, notadamente do processo civil.

Será abordado inicialmente o movimento moderno denominado de constitucionalização do processo, baseado no enaltecimento dos princípios constitucionais à luz dos quais se desenvolve o processo civil, expondo-se sua representatividade e reflexos na concepção, interpretação e aplicação das normas processuais, as últimas especialmente de interesse para o objeto deste trabalho, que procura emprestar maior amplitude ao princípio da razoável duração do processo consubstanciado no acesso à justiça e na efetividade da prestação jurisdicional.

A par das apontadas tendências, a inserção na legislação processual de instrumentos capazes de propiciar uma prestação célere e eficaz na composição dos litígios se impõe como ação imprescindível, ante às inovações tecnológicas que perpassam todas as áreas do conhecimento trazendo benefícios e avanços. Com o Direito Processual não poderia ser diferente.

É compreensível a preocupação e o receio de muitos diante do novo processo civil eletrônico, entretanto, apreensão semelhante se dera quando surgiu a máquina de datilografar, a 
qual fora seguida do computador e seus programas processadores de texto, como ferramenta a ser incorporada à atividade judiciária na prestação jurisdicional.

Percebe-se, portanto, que de tempos em tempos é preciso romper paradigmas. Ou alguém negaria hoje os benefícios trazidos com a informática e a eletrônica e defenderia a volta ao tempo da caneta e do papel?

\section{A CONSTITUCIONALIZAÇÃO DO PROCESSO - BALIZAMENTO PRINCIPIOLÓGICO}

$\mathrm{O}$ direito processual é fundamentalmente determinado pelo regime constitucional em que o processo se desenvolve. Alguns dos princípios gerais que o informam são precipuamente 1 princípios constitucionais ou seus corolários. Segundo a lição de Cintra, Grinover e Dinamarco:

A condenação metodológica e sistemática dos princípios constitucionais do processo toma o nome de direito processual constitucional.

Não se trata de um ramo autônomo do direito processual, mas de uma colocação científica, de um ponto-de-vista metodológico e sistemático, do qual se pode examinar o processo em suas relações com a Constituição.

O direito processual constitucional abrange, de um lado, (a) tutela constitucional dos princípios fundamentais da organização judiciária e do processo; (b) de outro, a

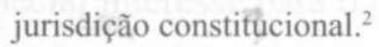

2 CINTRA, GRINOVER \& DINAMARCO. Teoria geral do processo: processo constitucional. 21. ed. São Paulo: Malheiros, 2005, p. 80-87.

Revista Esmat, Palmas, Ano 3, n 3, pag. 207 a 237 - jan/dez 2011 
O presente estudo se ocupa mais notadamente do primeiro aspecto mencionado, qual seja a tutela constitucional do processo, tomando-se por base as recentes reformas da legislação processual, dotadas de uma característica comum revelada por um direcionamento do legislador pela adequação das normas procedimentais, em razão da necessidade de se tornar o processo judicial mais ágil, e consequentemente, célere e efetivo, atendendo com maior eficiência os anseios dos jurisdicionados.

A prestação jurisdicional intempestiva pouco ou de nada serve para a parte que tem razão, constituindo-se em verdadeira denegação de justiça. E como efeito secundário e reflexo, a demora do processo desprestigia o Poder Judiciário e desvaloriza todos os envolvidos na realização do direito, quais sejam magistrados, promotores de justiça, defensores públicos, procuradores, advogados e servidores.

Além disso, o processo com duração excessiva tem graves repercussões sociais na medida em que constitui fonte de angústias e traz efeitos negativos a toda a coletividade, já que as pessoas se vêem desestimuladas a cumprir a lei quando sabem que outras a descumprem reiteradamente e obtêm manifestas vantagens, das mais diversas naturezas, destacando o professor Paulo Henrique dos Santos Lucon ${ }^{3}$ que:

3 LUCON, Paulo Henrique dos Santos. Duração razoável e informatização do processo nas recentes reformas. Disponível em: $<$ http://www.arcos.org.br/periodicos/revista-eletronicade-direito-processual/volume-vi/duracao-razoavel-e-informatizacao-do-proceso-nas-recentesreformas >. Acesso em: 24 mar 2011, às 16h24min. 
A primeira das vantagens é a econômica, pois são favorecidas a especulação e a insolvência, acentuando-se as diferenças entre aqueles que podem esperar (e tudo têm a ganhar com a demora da prestação jurisdicional) e os que têm muito a perder com a excessiva duração do processo. Entre adimplir com pontualidade e esperar a decisão desfavorável, ao devedor passa a ser muito mais vantajoso, patrimonialmente, a segunda opção.

A segunda delas é que a demora na outorga da prestação jurisdicional "aumenta os custos para as partes e pressiona os economicamente fracos a abandonar suas causas, ou a aceitar acordos por valores muito inferiores àqueles a que teriam direito".

Sendo assim, ante às históricas críticas e insatisfações relativas à prestação jurisdicional do Estado, resta questionada a instrumentalidade do processo, a qual deve ser revista em prol da minimização de tais aspectos, pois estes colaboram sobremaneira para o descrédito e afastamento do cidadão no que se refere ao acesso ao Judiciário.

Esta tendência revisional parte da concepção do processo a partir da Constituição Federal, de seus princípios e valores elementares, que sustentam o modelo adotado em nosso ordenamento. De princípios constitucionais basilares como acesso à justiça (ou garantias da ação e da defesa) e devido processo legal decorrem outros, como contraditório, ampla defesa, motivação das decisões, efetividade e celeridade, os dois últimos de especial interesse para o presente estudo.

O princípio da efetividade deve ser compreendido como valor inserto no direito de acesso à justiça, do qual o processo 
judicial é instrumento. A garantia do devido processo legal é a expressão desse direito, o qual enuncia a prerrogativa da parte postular em juízo, dentro de uma ordem jurídica justa, obtendo do Estado uma resposta, seja afirmativa ou negativa, acerca da tutela pretendida, ou, até mesmo, que sequer existam condições mínimas de se saber se há ou não o direito tutelado ${ }^{4}$.

Da conjugação dos incisos XXXV e LXXIV do artigo $5^{\circ}$ da Constituição Federal: "A lei não excluirá da apreciação do Poder Judiciário lesão ou ameaça a direito.” e "O Estado prestará assistência jurídica integral e gratuita aos que comprovarem insuficiência de recursos.", demonstra-se que o acesso à justiça envolve não apenas a garantia de acesso ao judiciário, mas à justiça em todas as suas manifestações, garantindo ao cidadão a eliminação de obstáculos que a dificultem, a ampliação das facilidades para concretização dos interesses judicialmente buscados e a diminuição dos custos do processo, fazendo com que um número cada vez maior de indivíduos possam litigar em juízo ${ }^{5}$.

O processo judicial nada mais é do que um instrumento de acesso à justiça, sendo certo que ao jurisdicionado não basta que se lhe assegure a prerrogativa de demandar, de pleitear a tutela que venha a satisfazer o interesse jurídico que o mova ao exercício do direito de ação. Imperioso é que o processo traga resultados práticos ao demandante, obtendo este os efeitos

\footnotetext{
4 BUENO, Cássio Scarpinella. Curso sistematizado de direito processual civil. São Paulo: Saraiva, 2007, p. 101-102.

5 ClemENTINO, Edilberto Barbosa. Processo judicial eletrônico. Curitiba: Juruá, 2008, p. 151-154.
} 
que almeja para o que, sem o processo, permanecer-lhe-iam inalcançáveis.

Diante de tal premissa, considera-se que os reflexos práticos da função jurisdicional exercida pelo Estado devem se fazer sentir pelo jurisdicionado, sob pena de ineficiência do poder-função, o que exige dos operadores do direito atenção voltada para esta realidade, notadamente ante à necessidade de que as inovações tecnológicas sejam absorvidas no âmbito processual a fim de facilitar ao processo a obtenção de resultados práticos.

Já o princípio da celeridade, consubstanciado no princípio da razoável duração do processo, deixou de ser um princípio ou valor sem aplicação prática imediata, o qual antigamente tinha que contar apenas com o bom senso dos julgadores e demais envolvidos na sua efetivação, para ser elevado, expressamente, pela Emenda Constitucional $\mathrm{n}^{\circ} 45$ à condição de direito fundamental do cidadão.

Como garantia da razoável duração do processo, intimamente ligado à noção de acesso à justiça, preceitua, fundamentalmente, que o processo não deve se perpetuar no tempo injustificadamente, retardando a entrega da prestação jurisdicional e privando os jurisdicionados da solução do conflito que os motiva a juízo.

Diz o artigo 5, inciso LXXVIII: "A todos, no âmbito judicial e administrativo, são assegurados a razoável duração do processo e os meios que garantam a celeridade de sua tramitação." Como se vê, o enunciado constitucional não impõe tão-somente 
uma aceleração do processo. Impõe-se a viabilização de meios a esse fim, bem como a inovação e melhora do modo de pensar e enxergar o processo.

É papel do direito processual fazer atuar as normas substanciais do modo mais efetivo possível e no menor espaço de tempo. Aliás, entende-se que a efetividade do processo está estreitamente relacionada com o seu tempo de duração.

Nesse sentido, em recente fala do ministro Luiz Fux, ainda membro do Superior Tribunal de Justiça e representando o presidente do STJ na abertura do Congresso Franco-Brasileiro de Estudos Jurídicos, destacou que em todas as declarações fundamentais do direito humano vem expressa a afirmação de que o País que não se desincumbe da prestação da justiça em um tempo razoável, é um país que tem uma justiça inacessível:

A razoabilidade de prazo é um conceito indeterminado. Um processo que tem dilações indevidas, que não permite à parte usufruir os resultados daquela prestação jurisdicional realmente não é um processo efetivo, porque não cumpre essa cláusula da duração razoável do processo ${ }^{6}$.

De acordo com o ministro, o sistema jurídico brasileiro tem empreendido todo tipo de reforma no afã de cumprir a duração razoável do processo, dentre elas o processo eletrônico. Ressaltou ainda que o processo eletrônico não muda o conceito de processo, sendo a única diferença o fato de que nele os atos

6 FUX, Luiz. O processo eletrônico importa em uma mudança de paradigma. Disponivel em: <http://www.stj.gov.br/portal stj/publicacao/engine.wsp?tmp.area=398\&tmp. texto $=93781>$. Acesso em 19 mar 2011, às $18 \mathrm{~h} 20 \mathrm{~min}$. 
são praticados por via eletrônica. Ainda em suas palavras:

\begin{abstract}
Nesse contexto, surge o processo eletrônico, um instrumento de expressiva agilização da prestação judicial. Só para os senhores terem uma idéia, os processos chegavam ao STJ, fisicamente, em sete meses. Hoje, com a maioria dos estados integrada ao sistema de digitalização, esses processos demoram menos de sete minutos para chegar ${ }^{7}$.
\end{abstract}

Seguindo essa linha de raciocínio, destacam-se outrossim os princípios da economia processual e da instrumentalidade, considerando-se que com a adoção do processo eletrônico no Brasil, o princípio da economia processual é ampliado, na medida em que proporciona menor desperdício na produção dos atos processuais. Não apenas em termos de valor financeiro relativamente à economia de dinheiro gasto com papel, mas também relativamente ao fato de que os tribunais de todo o país devem editar suas tabelas de custas minimizadas, advogados e procuradores evitarão gastos com custeio de transporte aos fóruns ou de passagens para deslocarem-se a diferentes comarcas ou ao Distrito Federal para acompanhamento processual. E em última análise, restando a prestação jurisdicional mais célere, é diminuído, via de consequencia, o custo da própria prestação jurisdicional.

O princípio da instrumentalidade, por sua vez, é consagrado nos artigos 154, 244 e 250 do Código de Processo

7 FUX, Luiz. O processo eletrônico importa em uma mudança de paradigma. Disponivel em: <http://www.stj.gov.br/portal stj/publicacao/engine.wsp?tmp.area=398\&tmp. texto $=93781>$. Acesso $\mathrm{em} 19 \mathrm{mar} 2011$, às $18 \mathrm{~h} 20 \mathrm{~min}$. 
Civil, com destaque para o primeiro, ao dispor que:

Os atos e termos processuais não dependem de forma determinada senão quando a lei expressamente a exigir, reputando-se válidos os que, realizados de outro modo, the preencham a finalidade essencial.

Percebe-se que a forma não é um fim em si mesma, sendo o processo, por definição, o instrumento através do qual a jurisdição se opera. ${ }^{8}$ E sendo assim, segundo a moderna teoria das nulidades processuais, todo ato processual é válido, independentemente de eventual defeito de forma, se o objetivo tiver sido alcançado. Como ensinam Cintra, Grinover e Dinamarco, "o que interessa, afinal, é o objetivo do ato, não o ato em si mesmo?."

É o que se percebe também na expressão "pas de nullité sans grief', do direito continental europeu, estatutário, bem como na denominação "substantive due process" do direito norte-americano, de origem consuetudinária.

O princípio da instrumentalidade das formas perpassa a disciplina teórica do processo e marca bem seu caráter instrumental, sendo de fundamental importância ao presente estudo, na medida em que se olha o processo judicial do ponto de vista do meio ou instrumento que pode incorporar os avanços da tecnologia da informação para a otimização do sistema

\footnotetext{
8 CINTRA, Antônio Carlos de Araújo, et al. Teoria geral do processo. 10 ed. São Paulo: Malheiros, 1994. p. 277

9 CINTRA, Antônio Carlos de Araújo, et al. Teoria geral do processo. 10 ed. São Paulo: Malheiros, 1994. p.343.
} 
processual e sua efetividade. O processo eletrônico, mesmo que realizado por meio físico especial, tem natureza jurídica de processo e qualifica-se como instrumento. Em outras palavras, o processo eletrônico absorve a tecnologia posta a serviço do Direito, com vistas a dar aplicação prática aos princípios constitucionais processuais acima mencionados.

Importante relevar que, em esquema de ponderação, os princípios quando orientadores da incorporação da tecnologia pelo sistema processual tem força inferior à dos mesmos princípios quando da jurisdição. O processo é instrumento. A técnica é instrumento do instrumento e deve ser tomada exatamente nesta medida subalterna de dupla subordinação.

Como salientado acima pelo ministro Luiz Fux, os princípios bemassentados do processo não podem sofrer regressão com a adoção das novas tecnologias e com o novo modo de fazer o processo. As milenares conquistas do Direito, expressas no universalmente aceito princípio do devido processo legal, não poderão ser maculadas pelos novos meios, tecnologicamente inovadores, adotados para a prática processual. A tecnologia deve ser posta a serviço da concretização das salvaguardas do devido processo, não contra elas, devendo sempre haver respeito inarredável aos direitos constitucionalmente consagrados e protegidos das pessoas ${ }^{10}$.

Retomando o embasamento principiológico do processo

10 PEREIRA, Sebastião Tavares. O processo eletrônico e o princípio da dupla instrumentalidade. Disponivel em: http://jus.uol.com.br/revista/texto/11824. Acesso em: dezenove de março do ano dois mil e onze, às $16 \mathrm{~h}$. 
eletrônico, nas palavras de José Carlos de Araújo Almeida Filho:

com a adoção do processo eletrônico no Brasil, o princípio da economia processual será alargado, porque haverá menos desperdício na produção dos atos processuais. $\mathrm{O}$ processo, em sua visão instrumentalista, necessita de meios para atingir ao seu fim, que é a pacificação da sociedade, como já dissemos inúmeras vezes. ${ }^{11}$

Finalmente, afirma-se que para a prestação jurisdicional eficaz e célere, há necessidade de um mecanismo que envolva todo o sistema jurídico instituído no país e todas as partes envolvidas no processo, devendo o legislador, consciente da impossibilidade prática de deixar a concretização dos princípios exclusivamente nas mãos dos sujeitos processuais e dos auxiliares da Justiça, envidar esforços para traduzir, legislativamente, a real aplicação deles.

\section{AS ORIGENS LEGISLATIVAS}

A própria Constituição incumbe-se de configurar o direito processual não mais como mero conjunto de regras acessórias de aplicação do direito material, mas, cientificamente, como instrumento público de realização da justiça. Reconhecendo a relevância da ciência processual, a Constituição atribui à União a competência para legislar sobre o direito processual, unitariamente conceituado (art. 22 , in. I) quanto a 'procedimentos em matéria processual', dá competência concorrente à União, Estados e ao Distrito

11

ALMEIDA FILHO, José Carlos de Araújo. Processo eletrônico e teoria geral do processo eletrônico: a informatização judicial no Brasil. 2. ed. Rio de Janeiro: Editora Forense, 2008. p. 89. 
Federal (art. 24, XI) ${ }^{12}$.

Antes do advento das recentes reformas, notadamente os trazidos pela Lei 11.419 , de 19 de dezembro de 2006, alguns esparsos dispositivos legais já conferiam pequena modernização ao processo por meio da disciplina da possibilidade da prática de atos por meios alternativos.

A Lei que dispõe sobre a informatização do processo judicial teve origem no Projeto de Lei 5.828/01, o qual nasceu de uma proposta da Associação dos Juízes Federais do Brasil AJUFE.

Acolhido pela Comissão de Participação Legislativa da Câmara em 2001, foi aprovado pelo plenário da Câmara em junho de 2002. No senado federal, o projeto recebeu parecer ' pela aprovação em forma de substitutivo legal, o qual foi aprovado pelo plenário desta casa em 07 de dezembro de 2005 e sancionado pelo Presidente da República em 19 de dezembro de 2006.

Em seu substitutivo, a relatora da Comissão de Constituição, Justiça e Cidadania, senadora Serys Slhessarenko, modificou substancialmente a versão original, sob o argumento de que desde sua apresentação já havia transcorrido mais de 5 anos, período em que teriam ocorrido vários progressos na área da informática, sendo necessárias adaptações no texto original para que fossem contemplados tais avanços tecnológicos que

12 CINTRA, GRINOVER \& DINAMARCO. Teoria geral do processo: processo constitucional. 21. ed. São Paulo: Malheiros, 2005, p. 80-87. 
proporcionassem maior agilidade, segurança e economia ao processo.

Assim, com a finalidade de que o contexto normativo acolhesse métodos mais modernos de prática dos atos jurisdicionais, o substitutivo incorporou atualização tecnológica e novas ferramentas jurídico-processuais, a exemplo do diário da justiça on line e o processo judicial totalmente virtual, considerando a internet como meio mais rápido e ágil de transmissão de informações, possível de ocorrer em tempo real em qualquer parte do mundo, bem como a preocupação de se dar suporte normativo e difundir as boas experiências dos Tribunais Regionais Federais e Tribunais do Trabalho, nos quais o processo virtual já era realidade.

O substitutivo também sugeriu alterações na forma prevista para citações e intimações, especialmente no que concerne à segurança do recebimento pelo destinatário, além de modificações no Código de Processo Civil para compatibilizá-lo com o uso do meio eletrônico. Nas palavras da senadora ${ }^{13}$ :

A virtualização do processo judicial traz vantagens incomparáveis, notadamente no que diz respeito ao acesso à Justiça, agilidade, transparência, economia. Para exemplificação, casos nos juizados especiais tiveram uma redução nos prazos médios de 765 dias, entre as datas de distribuição e da prolação da sentença, para menos de 50 dias.

Assim, como resultados primários da utilização do Processo

13 SLHESSARENKO, Serys. Parecer da Comissão de Constituição, Justiça e Cidadania sobre o projeto 5828/01. Disponível em: http://www.senado.gov.br/atividade/Materia/getPDF. asp?t=25193\&tp=1 Acesso em vinte e cinco de março de 2011, às $00 \mathrm{~h} 58 \mathrm{~min}$. 
Judicial Virtual e do Diário da Justiça On-Line, teremos a já referida agilidade da tramitação processual e da instantânea disponibilização da informação com transparência. E como resultados secundários, a maior difusão da informação que hoje, através da Internet, estaria acessível até em aldeias indígenas no meio da Amazônia; a preservação ecológica, com a redução de desmatamento e de gases tóxicos em face do abandono do uso do papel; assim como uma brutal redução de custos.

Em que pese não tenha sido da autoria da citada parlamentar, o substitutivo também passou a prever o método de certificação digital por meio de autoridade certificadora credenciada, diferentemente do texto original que previa apenas a identificação eletrônica através de cadastro do usuário junto ao Poder Judiciário.

Antes, porém, outras iniciativas legislativas foram tomadas visando à informatização do processo judicial, mesmo que com alcance tímido e limitado.

É o caso da Lei 9.800/99, conhecida como Lei do Fax, a qual admite a utilização de sistemas de transmissão de dados para a prática de atos processuais, tendo sido a primeira a autorizar o uso das tecnologias da informação para o desenvolvimento de sistemas de comunicação de atos processuais, rumo à virtualização completa. Entretanto, limitou-se a possibilitar o trânsito de petições em meio eletrônico, sendo que estas, chegando aos tribunais, eram impressas em papel e anexadas ao processo físico, já que a Lei obrigava as partes a entregar os “originais" em juízo. 
Não muito tempo depois, a Lei 10.259/01, que disciplinou a instituição dos Juizados Federais, trouxe em seu bojo três dispositivos que impulsionaram a informatização do processo perante esses órgãos especiais da Justiça Federal, quais sejam a recepção de peças processuais sem exigência de apresentação subseqüente de originais em meio físico; as reuniões por via eletrônica de juízes integrantes das turmas de uniformização jurisprudencial, quando domiciliados em cidades diferentes; e o desenvolvimento de programas de informática necessários para subsidiar a instrução das causas. Os departamentos de informática dos Tribunais Regionais Federais - TRFs desenvolveram a solução do "e-processo", conhecida simplesmente como "e-proc", o qual eliminou totalmente o uso do papel e dispensou o deslocamento dos advogados aos fóruns da Justiça Federal.

A primeira ação do JEF do RS foi julgada em apenas 04 horas, sendo o sistema de videoconferência inaugurado pela Turma Recursal dos Juizados Especiais Federais - JEFs de Santa Catarina em outubro de 2005, quando juízes em locais diferentes puderam participar da sessão de julgamento ${ }^{14}$.

Conforme dito anteriormente, tal legislação era adstrita aos Juizados Federais e não era dotada de técnicas que garantissem a identidade dos usuários, o que gerava críticas ao programa "e-proc".

Além dessas, a Lei 10.358/01, cujo intuito foi enfrentar

14 REINALDO FILHO, Demócrito. A uniformizatização do processo judicial - da Lei do Fax à Lei $\mathrm{n}^{\circ} 11.419 / 06$, uma breve retrospectiva legislativa.Disponivel em <http://jus.uol. com.br/revista/texto/9399>. Acesso em 17 mar 2011. 
o problema da autenticidade da identificação dos usuários do processo eletrônico, não prosperou, ante ao veto presidencial que teve como fundamento a decisão política de uniformizar a utilização da comunicação eletrônica, para que também no processo judicial fossem atendidos os critérios da Infra-Estrutura de Chaves Públicas Brasileiras - ICP-Brasil ${ }^{15}$.

Neste contexto, foi sucedida pela Lei $11.280 / 06$, a qual previu a validação dos atos processuais realizados em forma eletrônica perante todos os tribunais por meio da estrutura de certificação digital da ICP-Brasil, visto que à época já se encontrava editada a Medida Provisória n ${ }^{\circ} 2.200-2 / 01$, a qual instituiu a Infra-Estrutura de Chaves Públicas Brasileira - ICPBrasil, cuja função é a de "garantir a autenticidade, a integridade e a validade jurídica de documentos em forma eletrônica, das aplicações de suporte e das aplicações habilitadas que utilizem certificados digitais, bem como a realização de transações eletrônicas seguras" dotando-os de validade legal oponível contra todos.

A partir da Lei 11.280/06 o artigo 154 do Código de Processo Civil passou a contar com a seguinte redação em seu parágrafo único:

\section{Art. 154.(...)}

Parágrafo único. Os tribunais, no âmbito da respectiva jurisdição, poderão disciplinar a prática e a comunicação

15 CALMON, Petrônio. Comparação entre os parágrafos do art. 154 do CPC e a Lei no 11.419. Fonte: Comentários à Lei de informatização do processo judicial: Forense, 2007, p. 0309. 
oficial dos atos processuais por meios eletrônicos, atendidos os requisitos de autenticidade, integridade, validade jurídica e interoperabilidade da Infra-Estrutura de Chaves Públicas Brasileira - ICP - Brasil.

Neste ponto, abrem-se parênteses para a situação do artigo 154 do Código de Processo Civil. Isto porque após a referida inclusão de um parágrafo único pela Lei 11.280, a Lei 11.419 também acrescentou um parágrafo ao art. 154, denominando-o, a priori, de parágrafo único. A Presidência da República manteve os dois, por entender que o segundo não tinha o condão de revogar o primeiro ${ }^{16}$, entretanto nada mencionou a respeito da renumeração dos parágrafos. Portanto, assim ficou a redação do mencionado artigo:

\begin{abstract}
Art. 154. (...)
Parágrafo único. Os tribunais, no âmbito da respectiva jurisdição, poderão disciplinar a prática e a comunicação oficial dos atos processuais por meios eletrônicos, atendidos os requisitos de autenticidade, integridade, validade jurídica e interoperabilidade da Infra-Estrutura de Chaves Públicas Brasileira - ICP - Brasil."

$\S 2^{\circ}$ Todos os atos e termos do processo podem ser produzidos, transmitidos, armazenados e assinados por meio eletrônico, na forma da lei.
\end{abstract}

Percebe-se do dispositivo acima transcrito que o novo $\S 2^{\circ}$ trata da mesma matéria do parágrafo único, porém sem previsão da aplicação dos requisitos da ICP-Brasil. Havendo algumas

16 NEGRÃO, Theotonio, GOUVEA, José Roberto F. e BONDIOLI, Luis Guilherme A. Código de Processo Civil e legislação processual em vigor. 42. ed. São Paulo: Saraiva, 2010. 
variações de linguagem e estando coerentes com seus demais dispositivos, ambos subsistem e são aplicados em conjunto, valendo as regras normais de interpretação.

Retomando o curso cronológico das origens do processo eletrônico, tem-se que pouco tempo depois, sobreveio a Lei 11.341 também de 2006, a qual, dando nova redação ao artigo art. 541 do Código Processual Civil, possibilita ao recorrente, nos casos de recurso especial ou extraordinário fundado em dissídio jurisprudencial, a prova da divergência através de decisões disponíveis em mídia eletrônica, ou julgados disponíveis na internet, com indicação da respectiva fonte.

Ainda no mesmo ano, foi publicada a Lei 11.382, que alterou vários dispositivos do Código relativos ao processo de execução por título extra-judicial, criando os institutos da penhora on line e do leilão on line.

Também em 2006, especificamente em 28 de novembro, o Sistema de Restrição Judicial on line de Veículo Automotor (RENAJUD) foi implementado por Acordo de Cooperação Técnica firmado entre a União, por intermédio do Ministério das Cidades e do Ministério da Justiça, e o Conselho Nacional de Justiça. O objetivo de aludido sistema, segundo cláusula primeira daquele acordo, é permitir que restrições judiciais referentes à transferência, ao licenciamento, à circulação e ao registro de penhoras de veículos sejam cumpridas por meio eletrônico junto ao Registro Nacional de Veículos (Renavam).

E sendo assim, percebe-se que tais iniciativas representaram passos no caminho da informatização completa 
do processo, no afã de dar mais celeridade ao processo e fazêlo alcançar sua efetividade, sob a luz do princípio da duração razoável do processo, o qual se consagra, de modo mais amplo, com a referenciada Lei 11.419, de 19 de dezembro de 2006.

\section{O PROCESSO CIVIL ELETRÔNICO - LEI 11.419/2006 ${ }^{17}$}

Sua ementa autoriza os órgãos do Poder Judiciário a informatizar integralmente o processo judicial, para torná-lo acessível pela internet, ao dispor em seu artigo primeiro que: "O uso de meio eletrônico na tramitação de processos judiciais, comunicação de atos e transmissão de peças processuais será admitido nos termos desta Lei."

Em que pese haja quem diga que o mais pertinente seria a utilização da expressão procedimento eletrônico, haja vista que o que está em questão é "o meio extrínseco pelo qual se instaura, desenvolve-se e termina o processo; é a manifestação extrínseca deste, a sua realidade fenomenológica perceptível. ${ }^{18}$ ", adota-se a terminologia do próprio legislador posta na Lei 11.419/2006, ou seja, processo eletrônico.

A comentada Lei deve ser aclamada como o marco regulatório da informatização processual no Brasil, na medida em que contém um completo tratamento legal para

17 BRASIL. Lei n 11.419, de 19 de dezembro de 2006. Disponível em: <http://www. planalto.gov.br/ccivil_03/_Ato2004-2006/2006/Lei/L11419.htm> . Acesso em 19 mar 2011, às $01 \mathrm{~h} 21 \mathrm{~min}$.

18 CINTRA, Antônio Carlos de Araújo, et al. Teoria Geral do Processo. 17.ed. São Paulo:Malheiros, 2000. p. 277. 
o processo informatizado, abrangendo todas as fases ou atividades em meio eletrônico indispensáveis à implantação do processo informatizado em todo e qualquer órgão da Justiça, independentemente de seu grau de jurisdição. Seu art. $8^{\circ}$ traz regra destinada a materializar, na prática, a possibilidade autorizada pela própria lei da formação de um processo completamente digitalizado, sem qualquer peça ou ato registrado em suporte físico palpável (como o papel), ao estabelecer que "os órgãos do Poder Judiciário poderão desenvolver sistemas eletrônicos de processamento de ações judiciais por meio de autos total ou parcialmente digitais, utilizando, preferencialmente, a rede mundial de computadores e acesso por meio de redes internas e externas.", considerando ainda (em seu art. 11), que os documentos produzidos eletronicamente e juntados aos processos eletrônicos com garantia da origem e de seu signatário serão considerados originais para todos os efeitos legais.

A Lei $11.419 / 06$, portanto, adota como própria a validade de todas as atividades necessárias à implantação de um processo totalmente eletrônico, enquanto que as leis precedentes se limitaram a tentar informatizar fases, atos ou aspectos específicos do trâmite processual. A partir dela, todo e qualquer ato processual realizado por meio eletrônico recebe a presunção legal de validade se realizado exclusivamente por esse meio.

A autenticidade do usuário é assegurada por meio de uma assinatura digital, baseada em certificado formado por um conjunto de dados eletrônicos que vincula a assinatura e a sua respectiva chave a uma determinada pessoa, identificada como 
proprietária daquela chave, cadastrada no Poder Judiciário, com base em registros que devem ser mantidos pela autoridade certificadora, ICP-Brasil.

$\mathrm{O}$ próprio diário da justiça on line, criado pelo art. $4^{\circ}$ desta Lei deve ser disponibilizando em site da rede mundial de computadores, para publicação dos atos judiciais eadministrativos dos órgãos a ele subordinados, bem como comunicações em geral, devendo também serem assinados digitalmente com base em certificado emitido pela referida autoridade certificadora credenciada.

Reforçando esse caráter de materialização da possibilidade de formação do processo inteiramente digital, relevante destacar que as intimações são também reguladas por meio eletrônico em portal próprio, dispensando, inclusive a publicação no diário eletrônico e sendo consideradas pessoais para todos os efeitos legais.

Portanto, a Lei $\mathrm{n}^{\circ} 11.419 / 06$ é muito mais abrangente do que suas antecessoras, visto que tem o duplo objetivo de conferir maior celeridade ao processo e modernizar a justiça brasileira, consoante se vê da exposição de motivos. Tanto é verdade que autoriza a comunicação de atos e a transmissão de peças processuais por meio eletrônico, indistintamente, aos processos civil, penal e trabalhista, bem como aos juizados especiais, em qualquer grau de jurisdição.

Estabelece ainda a obrigatoriedade de que todas as pessoas que mantêm cadastros de informações necessárias a alguma decisão judicial passem a oferecer acesso eletrônico a 
esses cadastros para uso dos órgãos judiciários, sendo que em determinados casos, a intimação por meio eletrônico poderá substituir a intimação efetuada por meio da imprensa oficial. Interessante notar no $\S 5^{\circ}$ do artigo $5^{\circ}$ preocupação do legislador acerca da segurança e o louvor ou princípio da instrumentalidade ao dispor que:

Art. $5^{\circ} .(\ldots)$

$\S 5$ o Nos casos urgentes em que a intimação feita na forma deste artigo possa causar prejuízo a quaisquer das partes ou nos casos em que for evidenciada qualquer tentativa de burla ao sistema, o ato processual deverá ser realizado por outro meio que atinja a sua finalidade, conforme determinado pelo juiz.

Como serão feitas preferencialmente por meio eletrônico , todas as comunicações oficiais entre órgãos do Poder Judiciário e deste entre os demais Poderes da Federação, significa dizer que as cartas precatórias, rogatórias, de ordem e ofícios em geral, serão operacionalizados por meio eletrônico, o que evidentemente agilizará o andamento do processo judicial.

Algumas das inovações da Lei, acredita-se, podem ser imediatamente implantadas pelo Poder Judiciário, com alguns ajustes na praxe dos cartórios. Outras, entrentanto, podem levar um pouco mais de tempo para serem implantadas já que será necessário o desenvolvimento por parte de cada órgão de sistemas eletrônicos de processamento de ações judiciais por meio de autos total ou parcialmente digitais, disponibilizados às partes por meio da rede mundial de computadores. 
Nesse contexto, advogados não necessitarão fazer-se presentes em cartórios ou secretarias judiciais, já que procederão a atos processuais tais como a distribuição de petição inicial, apresentação de defesa e interposição de recursos pelo seu computador, onde quer que esteja. Da mesma forma o magistrado, poderá realizar despachos e decisões monocráticas com maior mobilidade.

Relevante destacar, outrossim, a fruição dos prazos processuais que poderão ser aproveitados pelas partes e seus advogados até as $23 \mathrm{~h} 59 \mathrm{~min}$ do último dia de cada prazo previsto, não prosperando mais a vinculação do último dia de prazo ao último minuto do expediente forense.

Interessante observar que a lei estabelece que "os autos dos processos eletrônicos deverão ser protegidos por meio de sistemas de segurança de acesso e armazenados em meio que garanta a preservação e integridade dos dados, sendo dispensada a formação de autos suplementares". Como se sabe, proteger a memória de computadores é tema caro e objeto de grande preocupação da informática. Na atual conjuntura, verifica-se que se os autos de papel estão sujeitos a furto, incêndio, ratos, fungos ou à ação da água, há também riscos em relação aos dados eletrônicos. Entretanto, esses riscos são bem menores diante de novos sistemas de armazenamento de dados simples e comumente conhecidos como back up.

Ante à nova situação legislativa, espera-se que o Poder Judiciário cumpra as expectativas do legislador e da própria sociedade, desenvolvendo seus tribunais sistemas informáticos 
e programas aptos a suportar a consecução de todas as atividades processuais em meio eletrônico. Espera-se que a administração judiciária, em suas diferentes esferas, desenvolva sistemas dotados de capacidade para realizar eletronicamente o envio e recebimento de atos, a proteção da integridade e autenticidade dos textos recebidos e enviados e o seu armazenamento de forma confiável, além de possibilitar autenticidade aos usuários do sistema, quais sejam as partes, advogados, magistrados, promotores de justiça, servidores da justiça e outros.

Finalmente, percebe-se a intenção latente da Lei $\mathrm{n}^{\circ}$ 11.419/06 como sendo a de acelerar o procedimento judicial, conferindo a ele maior celeridade e eficácia. Ou seja, o legislador tentou tornar o método de trabalho mais dinâmico, adequando-o aos avanços tecnológicos, de modo a agilizar a prestação jurisdicional.

\section{CONSIDERAÇÕES FINAIS}

A busca por fórmulas para o alcance do ideal de processo justo foi e sempre será uma constante preocupação do legislador, dos doutrinadores e estudiosos do direito.

A morosidade da justiça tem funcionado historicamente como a grande vilã daqueles que buscam no Poder Judiciário a preservação de seus direitos. Como dito anteriormente, o descrédito do sistema ante a sua ineficiência é fator de afastamento do cidadão e de desestabilização social.

A satisfação do jurisdicionado, trazendo a quem tem razão 
e em tempo razoável, o bem jurídico perseguido na demanda, para que do mesmo goze em sua plenitude, representa a essência e a razão justificadora da própria atividade jurisdicional do Estado.

A necessidade de um sistema que possa facilitar o alcance desse ideal, sem que se agridam os direitos fundamentais constitucionalmente garantidos, exige o rompimento com antigos dogmas que injustificadamente persistem e impedem o avanço do processo por meio da aliança entre direito e tecnologia. Entre os instrumentos destinados a esse fim, o processo eletrônico surge como valorosa ferramenta.

Como visto, ele se apresenta de forma real e legítima, amparado na experiência bem sucedida de alguns ramos do Judiciário inseridos na sociedade informatizada e principalmente nos princípios processuais civis consagrados na Constituição Federal, devendo o processo acompanhar o tempo e o contexto social em que se realiza a fim de proporcionar uma justiça mais efetiva.

\section{REFERÊNCIAS BIBLIOGRÁFICAS}

\section{ALMEIDA FILHO, José Carlos de Araújo. Processo eletrônico e teoria geral do processo eletrônico: a informatização judicial no Brasil. 2 ed. Rio de Janeiro: Editora Forense, 2008.}

BRASIL. Lei n 11.419 , de 19 de dezembro de 2006. Disponível em: <http://www.planalto.gov.br/ccivil_03/_Ato2004- 
2006/2006/Lei/L11419.htm> . Acesso em dezenove de março de dois mil e onze, às $01 \mathrm{~h} 21 \mathrm{~min}$.

BUENO, Cássio Scarpinella. Curso sistematizado de Direito Processual Civil. São Paulo: Saraiva, 2007.

CALMON, Petrônio. Comparação entre os parágrafos do art. 154 do CPC e a Lei $n^{\circ} 11.419$. Fonte: Comentários à Lei de informatização do processo judicial: Forense, 2007, pp. 0309. Material da $4^{\mathrm{a}}$ aula da disciplina Fundamentos do Direito Processual Civil, ministrada no curso de Pós-Graduação Lato Sensu Televirtual em Direito Processual Civil - Anhanguera Uniderp/IBDP/Rede LFG.

, CINTRA, GRINOVER \& DINAMARCO. Teoria Geral do Processo: processo Constitucional. 21. ed. São Paulo: Malheiros, 2005, p. 80-87. Material da $3^{\text {a }}$ aula da disciplina Fundamentos do Direito Processual Civil, ministrada no curso de Pós-Graduação Lato Sensu Televirtual em Direito Processual Civil - Anhanguera Uniderp/IBDP/Rede LFG.

CINTRA, Antônio Carlos de Araújo, et al. Teoria geral do processo. 10. ed. São Paulo: Malheiros, 1994.

CLEMENTINO, Edilberto, Barbosa. Processo judicial eletrônico. Curitiba: Juruá, 2008. 


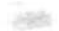

FUX, Luiz. O processo eletrônico importa em uma mudança de paradigma. Disponível em: <http://www.stj.gov.br/portal_stj/ publicacao/engine. $w s p ? t \mathrm{tmp}$. area $=398 \& \mathrm{tmp} \cdot \mathrm{texto}=93781>$. Acesso em dezenove de março de dois mil e onze, às $18 \mathrm{~h} 20 \mathrm{~min}$.

LUCON, Paulo Henrique dos Santos. Duração razoável e informatização do processo nas recentes reformas. Disponível em: <http://www.arcos.org.br/periodicos/revista-eletronicade-direito-processual/volume-vi/duracao-razoavel-einformatizacao-do proceso-nas-recentes-reformas $>$. Acesso em: vinte e quatro de março do ano dois mil e onze, às $16 \mathrm{~h} 24 \mathrm{~min}$.

NEGRÃO, Theotonio, GOUVEA, José Roberto F. e BONDIOLI, Luis Guilherme A. Código de Processo Civil e legislação processual em vigor. 42. ed. São Paulo: Saraiva, 2010.

PEREIRA, Sebastião Tavares. O processo eletrônico e o princípio da dupla instrumentalidade. Disponível em: $<$ http://jus.uol.com. br/revista/texto/11824>. Acesso em: dezenove de março do ano dois mil e onze, às $16 \mathrm{~h}$.

REINALDO FILHO, Demócrito. A uniformizatização do processo judicial - da Lei do Fax à Lei n ${ }^{\circ} 11.419 / 06$, uma breve retrospectiva legislativa.Disponível em <http://jus.uol.com.br/ revista/texto/9399>. Acesso em dezessete de março de dois mil e onze. 
SLHESSARENKO, Serys. Parecer da Comissão de Constituição, Justiça e Cidadania sobre o projeto 5828/01. Disponível em: <http://www.senado.gov.br/atividade/Materia/getPDF. asp? $\mathrm{t}=25193 \& \mathrm{tp}=1>$ Acesso em vinte e cinco de março de dois mil e onze, às $00 \mathrm{~h} 58 \mathrm{~min}$. 